\title{
Non-Contiguous Disease
}

National Cancer Institute

\section{Source}

National Cancer Institute. Non-Contiguous Disease. NCI Thesaurus. Code C39768.

A term that usually refers to the clinical course of lymphomas and indicates that the cancerous lymph nodes are not next to each other, but are on the same side of the diaphragm. 